\title{
First-Person Authority and Self-Knowledge as an Achievement
}

\author{
Josep E. Corbí | University of Valencia \\ European Journal of Philosophy, v. 18, No. 3, pp. 325-362
}

Abstract: There is much that I admire in Richard Moran's account of how first- person authority may be consistent with self-knowledge as an achievement. In this paper, I examine his attempt to characterize the goal of psychoanalytic treatment, which is surely that the patient should go beyond the mere theoretical acceptance of the analyst's interpretation, and requires instead a more intimate, first-personal, awareness by the patient of their psychological condition.

I object, however, that the way in which Moran distinguishes between the deliberative and the theoretical attitudes is ultimately inconsistent with a satisfactory account of psychoanalytic practice; mainly because, despite Moran's claims to the contrary, such a distinction is still inspired by a Cartesian picture of the self. I argue that, in the light of his distinction, Moran may emphasize that an agent's psychological dispositions should be permeable to her decisions and projects, but is forced to reject the idea that permeability could go the other way too. I explore Bernard Williams' notion of acknowledgment and Simone Weil's distinction between two notions of necessity, in order to articulate a notion of receptive passivity which may help us to characterize this second direction of permeability. I finally outline why receptive passivity (and, thereby, the double direction of permeability) is crucial in order to identify the goal of psychoanalytic treatment and, derivatively, to understand how a certain kind of awareness may have a significant therapeutic effect.

\section{The Issue}

The Parallel Campaign was designed as an essentially Austrian project to celebrate the 70th jubilee of Emperor Franz Josef in 1918. It was, nevertheless, meant to counteract the effects of a similar campaign organized by Germany for the 30th jubilee of their Emperor, Wilhelm II. Diotima, a charming and well-educated lady, hosted the inaugural session of the Parallel Campaign and, in a significant breach of protocol, she invited Arnheim, a prominent Prussian, to join the meeting. As 
the narrator, in Robert Musil's The Man without Qualities, remarks, this slip was due to the fact that Diotima was in love with her guest, even if she 'had no inkling of the nature of her feeling'.1

If Rachel, Diotima's graceful servant, had asked the latter whether she meant to invite Arnheim to the inaugural session, Diotima might have answered 'Yes'. And not even such a thought-provoking writer as Musil would have doubted Diotima's epistemic authority in this respect. Neither might Musil have tried to detail the evidence in virtue of which Diotima might have acquired such a robust piece of self-knowledge. A demand for evidence could only have been proposed as a sort of joke, but hardly to reveal a deeper truth about Diotima's psychological condition. The standard debate about self-knowledge tends to focus on the sort of first-person authority that is revealed by the fact that Diotima's self-ascription of her intention to invite Arnheim cannot be reasonably be challenged, except by lack of sincerity. In such a case, no one could reasonably ask Diotima to provide evidence to support her claim and the impertinence of this question enhances, rather than defies, her epistemic authority on the matter.

Yet, when it comes to other psychological states or dispositions, Diotima's authority is less clear. If Diotima had been asked whether she was actually in love with Arnheim and she had sincerely declared that she wasn't, the narrator could have easily challenged her declaration and not only on the charge of insincerity. The narrator actually appeals to Diotima's inexperience to account for her blindness, and gestures at her outstanding breach of protocol, in an otherwise very correct lady, as a symptom of a hidden motivation. Part of the lure of Musil's novel lies in the narrator's ability to investigate a character's psychological condition beyond the latter's own views and to intermingle the narrator's, the reader's and the character's perspective to shed some light on the latter's psychological condition and her capacity to lead an authentic life. In fact, the narrator assumes that he knows better than Diotima herself what the latter's ultimate hopes, fears, and expectations are. Varying from case to case, it may be more or less reasonable to challenge Diotima's self-ascription of some mental states and, correspondingly, ask her to provide evidence in support of her claims. The kind of unconscious motives stipulated by psychoanalysts constitute an extreme case in an array of ways in which an agent may keep out of sight some of her own states and motivations. ${ }^{2}$

It seems, then, that a satisfactory account of first-person authority must take into consideration that there is a significant number of cases where a third party may know better than the agent herself whether she is in a certain psychological condition. In other words, there are some cases where self-knowledge must be regarded as an achievement, and not a trivial one. For having a certain kind of access to one's own psychological states may be crucial to one's capacity to 
lead one's life.

\section{Structure and Style}

Richard Moran proposes a rather novel and illuminating account of how first-person authority may be consistent with self-knowledge as an achievement. His approach emphasizes two aspects that are neglected within the received Cartesian model, namely: the role of practical commitment in self-knowledge as well as the permeability of psychological dispositions to deliberation. I will argue, however, that his approach is still trapped within the Cartesian model in some crucial respects. To this end, I will examine Moran's account of the kind of awareness that may have a healing effect on an agent's psychic health. The individuation of such kind of awareness is presented by Moran as a significant virtue of his approach and, to this purpose, he introduces a few notions such as permeability, transparency, and avowal. I will argue however that, even if these notions go in the right direction, they are in need of substantial modification if they are to apprehend the relevant kind of awareness. I will, in part II, take advantage of Bernard Williams' notion of acknowledgment, ${ }^{3}$ as well as Simone Weil's distinction between two notions of necessity, ${ }^{4}$ in order to articulate the sort of substantial modification that I judge indispensable. I will argue, more specifically, that a certain kind of receptivity plays a crucial role in understanding the repairing virtues of awareness, even though such receptivity may conflict in more than one way with Moran's fundamental distinction between the deliberative and the theoretical attitude towards oneself.

Before closing this introduction, let me briefly motivate the philosophical style that inspires this paper. It seems clear that philosophy has to do with the discernment of some facti and, therefore, that a philosopher must try to get in contact with the particular factum whose aspects she wants to discern. This contact is only possible if she explores some paradigmatic cases, if she looks carefully into them. Needless to say, identifying a case as paradigmatic already involves some philosophical abilities. One may resort to the philosophical, scientific or literary tradition to identify them. And it is already a philosophical view that some philosophical trends have lost sight of the relevant factum, that what they regard as paradigmatic is not.

One significant way of losing sight of the subject matter is by pressing too much in the direction of clarity or raising questions which, even if they are well-entrenched in the philosophical tradition, may not be relevant to the issues at hand. In the discussion that follows, I have tried to avoid this pitfall. This paper constitutes both a vindication of and an exercise in a philosophical style that distrusts an excessive emphasis in principles, definitions, thought 
experiments, and qualifications, but insists on looking into paradigmatic cases, drawing connections and taking them just to the point at which they stop being illuminating.

First-person Authority: Deliberative vs. Theoretical Attitude

\section{The Akratic Gambler}

Moran's approach to first-person authority can be quite naturally presented (and discussed) in the light of the akratic gambler's case. Suppose that, at some point, the akratic gambler reflects on the impact of gambling on his life and, as a result, he decides not to gamble anymore. Yet, he soon realizes that he had previously made similar decisions to no avail, since he ended up gambling even more intensely than before. So, he may predict that, despite his best intentions, he will after all keep on gambling and, as a result, he will ruin himself and his family. He may even seek to use his decision as a barrier against his drive and, in this respect, he will regard his own decision as a sort of countervailing force. ${ }^{5}$

We may express what is going wrong with the akratic gambler by saying that his psychological dispositions are not sufficiently permeable to his decisions. It seems, then, that a certain degree of permeability is constitutive of our notion of a healthy agent. And if, in his plight, the akratic gambler indulged in his psychological dispositions and accepted that there is nothing that he can do with regard to them, then he will be evading his responsibility as an agent who is supposed to make decisions, form intentions, and, therefore, acquire some commitments with regard to some future action. But if, on the contrary, he neglected the strength of his psychological disposition and assumed that, by making the appropriate decision, his life will change; then he would be prey to another sort of evasion. ${ }^{6}$ It is a relevant aspect of an agent's psychic health that she does not systematically indulge in any such evasion. For no one could evade herself in any of these two ways systematically, and still be regarded as an agent.

\section{The Deliberative vs. the Theoretical Attitude}

Following up on Moran, we could thus claim that agency is placed in the interplay between a deliberative and a theoretical attitude towards him or herself. ${ }^{7}$ The deliberative attitude is involved in the gambler's capacity to decide not to gamble again, while he adopts the theoretical attitude when he 
contemplates his psychological dispositions and predicts that he will gamble again.

Self-ascriptions based on a deliberative attitude seem to be endowed with first-person authority. No evidence needs to be provided on the agent's side and, relatedly, she needn't look into her behavior in order to find out what she has finally decided or the intention she has finally formed. Here the asymmetry with a third party is manifest. For the latter has to rely on the agent's behavior (including her self-ascriptions) to know what the agent's intentions are.

By contrast, self-ascriptions on the basis of a theoretical attitude upon oneself do not seem to possess the kind of first-person authority we are trying to grasp at this stage. For, obviously, the agent must look for evidence in order to make the appropriate statements of fact and, consequently, she could legitimately be asked to support her claims on some evidence. Moreover, quite often the agent is not in a better position than a third party to gather the relevant evidence to make that kind of ascription.

In this respect, we could only establish that the agent has a privileged theoretical situation if we assumed that the evidence to be gathered is fundamentally concerned with events and states to which only the agent has a direct access. Independently of whether one could coherently fix the content of such states and events, ${ }^{8}$ we can hardly take this Cartesian assumption as the starting point, the raw material, of our reflection about self-knowledge. For much of its attraction derives from a rather elaborated philosophical position, namely: the foundationalist attempt to answer skeptical arguments. ${ }^{9}$ In any case, Moran points to a second worry that this approach, and any theoretical view about self-knowledge, must confront, namely: that theoretical access to oneself is not first-personal enough. ${ }^{10}$ For, within such a perspective, one regards one's own thoughts and sensations as a mere passing show, as not involving any sort of commitment on the agent's side. ${ }^{11}$ One observes and describes one's own thoughts and emotions with the same attitude as one could observe and describe someone else's.

According to Moran, the lack of first-person authority and the fact that theoretical selfknowledge is not first-personal enough are closely interlocked: it is because theoretical selfknowledge is not first-personal enough that the agent lacks first-person authority with regard to the facts thus discovered. On his approach, an agent's authority involves two aspects. An agent has, first of all, the authority to commit herself to perform a certain action by forming an intention or by making a decision. ${ }^{12}$ And it is in virtue of the agent having this sort of, say, practical authority that she is endowed with epistemic authority with regard to her self-ascriptions of intentions or decisions. This connection must be regarded as a conceptual one. For it is difficult to imagine a situation where a certain agent is deprived of epistemic authority about certain kinds of intentions 
and decisions, and we still endow her with the corresponding practical authority.

In any case, Moran introduces the notion of permeability to understand what that interplay may amount to: an agent's psychological dispositions and states must be to some degree permeable to the results of her deliberations. A minimal degree of permeability is required to be an agent at all, while falling below a certain degree of permeability is a criterion of psychic impairment. In the next section, I will present some other concepts that Moran introduces in order to explore the phenomenon of permeability. I regard this phenomenon as crucial, but I will argue that a proper understanding of it will ultimately lead us to (a) revise the role that Moran attributes to the theoretical attitude in an agent's life, (b) vindicate the role of a specific sort of perception or receptivity as being relevantly first-personal. All this will (c) improve our understanding of what is involved in the deliberative attitude and the kind of awareness that may have a healing effect.

\section{The Transparency Condition}

In his Introductory Lectures to Psychoanalysis, Freud begins his presentation of a general theory of neurosis with the case of a high-class married lady, say, Frau Bruggen, whose neurotic symptoms he regards as a displacement of a monstrous passion: her being in love with her son-in-law. As Freud himself puts it:

She herself was intensely in love with a young man, with the same son-in-law who had persuaded her to come to me as a patient. She herself knew nothing, or perhaps only a very little, of this love; in the family relationship that existed between them it was easy for this passionate liking to disguise itself as innocent affection. After all our experiences elsewhere, it is not hard for us to feel our way into the mental life of this upright wife and worthy mother, of the age of fifty-three. Being in love like this, as a monstrous and impossible thing, could not become conscious; but it remained in existence and, even though it was unconscious, it exercised a severe pressure. Something had to become of it, some relief had to be looked for; and the easiest mitigation was offered, no doubt, by the mechanism of displacement which plays a part so regularly in the generating of delusional jealousy. If not only were she, the old woman, in love with a young man, but if also her old husband were having a love affair with a young girl, then her conscience would be relieved of the weight of her unfaithfulness. The phantasy of her husband's unfaithfulness thus acted as a cooling compress on her burning wound. (Freud 1973: 291) 
We have here a case where blindness towards the nature of one's own experience and, more precisely, the experience of being in love, gives rise to some neurotic symptoms which psychoanalytic treatment is meant to heal by bringing it to the patient's consciousness. Part of the problem lies in specifying the kind of awareness that may have such a healing effect; for some sorts of awareness are not only useless, but standardly interpreted as a resistance on the agent's side. Moran's notion of avowal certainly seeks to shed some light on the kind of awareness that may contribute to restore the patient's psychic health. I will argue, however, that, even if the notion of avowal is illuminating in many respects, it is ultimately inadequate because it is trapped within Moran's distinction between the deliberative and the theoretical attitudes. ${ }^{13}$

To introduce his notion of avowal, Moran invites us to consider how an agent's answer to question

(a) 'Do I believe that P?'

may relate to her answer to question

(b) 'Is P true?'

Even if these two questions are not equivalent, it seems that, at least in the standard case, the agent must answer both questions in the same way. This implies that, in such cases, the agent should not answer (a) by looking on her inner theatre to see whether she has a certain belief, but by deliberating about what the right answer to question (b) might be. In so doing, she must explore the world in order to determine whether P is true. Hence, the fact that (a) and (b) satisfy $a$ Transparency Condition (i.e., that they are transparent to one another insofar as the agent must answer (a) ' $\ldots$ by reference to (or consideration of) the same reasons that would justify an answer to the corresponding question about the world') $)^{14}$ implies that (a) is construed as a deliberative question and, consequently, that, in raising that question, the agent is adopting a deliberative attitude towards herself.

The Transparency Condition, as it stands, highlights a conceptual connection between (a) and (b), whenever the former is raised in a deliberative manner. We may thus say that this condition is trivial, since as it only requires on the agent's side that she should be able to adopt a deliberative attitude towards (a). And even Frau Bruggen, impaired as she is, has no trouble in adopting such an attitude towards the question 'Do I believe that my husband has betrayed me?' 
For her negative answer to the question was the result of a process of deliberation guided by the same reasons that led her to answer the corresponding (b)-question (i.e., 'Is it true that my husband has betrayed me?') in a certain way and, as a result, the Transparency Condition is met.

There are, however, some other situations where (a) should rather be interpreted in a theoretical manner; think, for instance, of those situations where there is a mismatch between what the agent sincerely claims to believe and what her behavioral dispositions may reveal she is believing. ${ }^{15}$ Frau Bruggen may be convinced that her husband has not betrayed her and, nevertheless, her obsessive behavior still manifests that there is a relevant sense in which she keeps on believing that her husband has betrayed her. To determine whether this believing persists, question (a) should be raised from a theoretical perspective:

(a*) Is 'believing $\mathrm{P}^{\prime}$ among my behavioral dispositions?

It is easy to see that, in this case, the fact that question-( $\left.a^{*}\right)$ is transparent to question-(b) is no longer a trivial matter for the agent, but comes up as a significant achievement, as Moran himself highlights: ${ }^{16}$

There are, however, other possible situations calling for a different perspective on oneself, and from the stance of an empirical spectator one may answer the question of what one believes in a way that makes no essential reference to the truth of the belief, but is treated as a more or less purely psychological question about a certain person, as one may inquire into the beliefs of someone else. If I have reason to believe that some attitude of mine is not 'up to me' in this sense, that is, for example, some anger or fear persisting independently of my sense of any reasons supporting it, then I cannot take the question regarding my attitude to be transparent to a corresponding question regarding what it is directed upon. Transparency in such situations is more of an achievement than something with a logical guarantee. (Moran 2001: 67)

Moran often stresses that an agent's psychological states and attitudes must be responsive (or permeable) to the result of her practical deliberations. And this is a conceptual constraint that comes in different degrees. A minimal degree of responsiveness is required to individuate a human being as an agent at all, whereas a higher degree may be demanded to recognize such an agent as rational or healthy. This conceptual constraint is, nevertheless, consistent, as Moran himself 
remarks, with rather specific mismatches between the outcome of one's deliberations and one's actual psychological dispositions, as it happens in Frau Bruggen's and the akratic gambler's case. And, in those circumstances, making one's psychological dispositions transparent to one's deliberations comes as a significant achievement, as a criterion of one's recovery.

Moran takes for granted, however, that a single Transparency Condition is at stake in the two situations we have been examined so far, namely: one in which the agent is simply asked to adopt a deliberative attitude towards (a), and another in which she is required to render her psychological dispositions permeable to her answer to question (b). Yet, it is hard to see how these two demands could be equivalent, since the former is trivially satisfied by any human being that could be identified as an agent at all, whereas only healthy agents may meet the latter to a relevant degree. Moreover, we can only make sense of Frau Bruggen's predicament (and also of that of the akratic gambler, although in the latter case some modifications are required in order to adapt the transparency condition to intentions and decisions, which undoubtedly form a part of the deliberative attitude) if we assume that she fulfills the trivial requirement, but fails to meet the more demanding one. We know that, in the light of evidence, Frau Bruggen came to believe that her husband has not betrayed her, whereby we may say that, in acquiring such a commitment, she has raised the relevant (a)-question as transparent to the corresponding (b)-question, since her response to either question was motivated by the same reasons. So, we may say that she satisfies the following constraint:

The Trivial Condition of Transparency: the answer to question 'Do I believe that P?' is transparent to the question 'Is $\mathrm{P}$ true?' if and only if the former question is answered by the same reasons that would justify an answer to the latter.

This is, in fact, the only constraint that Moran explicitly mentions as a condition for transparency. Frau Bruggen's obsessive behavior constitutes, though, a standard psychoanalytic case and, therefore, we must interpret her predicament as one in which those beliefs of hers which satisfy this trivial condition of transparency are, nevertheless, in conflict with what her obsessive behavior reveals she keeps on believing. To put it another way, Moran should just say that Frau Bruggen's psychological dispositions are not sufficiently permeable to the beliefs she is (trivially) committed to. To increase such permeability and, therefore, render Frau Bruggen's psychological dispositions transparent to her answer to question (b), will certainly count as an achievement, as a criterion of her recovery. So, a second, deeper, condition of transparency seems to be in place: 
The Deeper Condition of Transparency: the answer to the question 'Is "believing that P" among my behavioral dispositions?' is transparent to the question 'Is P true?' if and only if the behavioral dispositions relevant to my believing that $\mathrm{P}$ are permeable to the reasons that would justify an answer to the latter question.

This condition of transparency is certainly parasitic upon the trivial one: only agents whose beliefs are transparent in the trivial sense may aim at satisfying the deeper condition. And this is what Frau Bruggen (and the akratic gambler) fail to do. So, it seems that, if we are to describe Frau Bruggen's (and the akratic gambler's) plight in terms of Moran's Transparency Condition, we are forced to differentiate two conditions of transparency: a trivial and a deeper one. I will further object, however, that the distinction between these two conditions of transparency (as well as the corresponding notions of avowal) is insufficient to characterize the goal of psychoanalytic treatment unless Moran's approach is repaired in a rather significant way. To see this, let us first show how the ambiguity in the transparency condition expands into Moran's notion of avowal.

\section{Avowals and The Goal of Psychoanalytic Treatment}

\subsection{The Ambiguity of Avowals}

Frau Bruggen asked herself whether she had been betrayed by her husband. She examined the relevant facts, she concluded that she hadn't and she, thereby, acquired a certain belief; insofar as that belief is the result of a proper examination of the relevant facts, we may say that it satisfies the trivial condition of transparency or, in Moran's terms, the Transparency Condition tout court.

Whenever she might decide to declare her belief, her declaration will thereby count as an avowal:

The notion of avowal has been developed here in relation to the earlier idea of transparency. A statement of one's belief about X is said to obey the Transparency Condition when the statement is made by consideration of the facts about $\mathrm{X}$ itself, and not by either an 'inward glance' or by observation of one's own behavior. An avowal is a statement of one's belief which obeys the Transparency Condition. (Moran 2001: 101) ${ }^{17}$

We may regard this notion of avowal as trivial insofar as it just requires that the agent's declaration should be trivially transparent. We know that, despite Frau Bruggen's grounded conviction that her husband has not betrayed her, she actually displays a pattern of behavior that suggests that she 
still believes that her husband has betrayed her. Someone may suggest this to her and she may accept, in the light of some evidence, that her believing that her husband has betrayed her still forms a part of her behavioral dispositions. And, nevertheless, the acceptance of such a fact about herself will not entitle her to (trivially) avow that her husband has betrayed her because such believing does not satisfy the trivial condition of transparency.

The rationality of her response requires that she be in a position to avow her attitude toward him, and not just describe or report on it, however accurately, for it is only from the position of avowal that she is necessarily acknowledging facts about him as internally relevant to that attitude (say, as justifying or undermining it), and thereby (also) as relevant to the fully empirical question of whether it remains true that she indeed has this sense of being betrayed by him. (Moran 2001: 93)

The mismatch between what a agent may trivially avow and her beliefs as they are displayed by her behavioral dispositions, led us to introduce the deeper condition of transparency. We may, then, propose a corresponding notion of avowal, namely: an agent deeply avows her beliefs whenever the latter are deeply transparent. The question now is how this deeper notion of avowal may help us to understand psychoanalytic practices. I will argue that this notion, as it stands, cannot coherently characterize the goal of such practices; for a second direction of permeability is actually needed. Moran insists that our psychological dispositions should be permeable to our decisions and deliberations; my point is that we must also make sense of the idea that our decisions and deliberations should be permeable to our psychological dispositions if we want to appropriately characterize the kind of awareness that may have healing effects. In particular, I will try to grasp this second direction by exploring a certain way in which an agent may be passive, which crucially contrasts with the way in which the akratic gambler or Frau Bruggen are passive as they indulge in their respective obsessive behavior. My worry will then be that this notion is inconsistent with the relevance attached, within Moran's approach, to the distinction between the deliberative and the theoretical attitudes.

In a first approximation, we could say that a psychoanalyst treats unconscious motives as motives that are impervious to the agent's commitments. And, as a result, we may initially think that the goal of treatment consists of rendering a patient's psychological attitude permeable to her own commitments. Psychoanalysts seem to assume that at least one means by which this goal can be achieved is by rendering their patient aware of her initially unconscious desires. It is clear that 
the kind of awareness required cannot reduce to a statement of fact about the unconscious desire that supposedly accounts for the obsessive pattern of behavior. Nobody doubts nowadays that Frau Bruggen could not be cured by just accepting, in the light of evidence, that she was in love with her son-in-law. The kind of awareness that she should have of that fact must certainly go beyond that sort of acceptance.

A relevant novelty in Moran's approach lies in his attempt to offer an appropriate characterization of the kind of awareness involved in such cases. He certainly uses the notion of avowal to characterize the goal of psychoanalytic treatment and, even if he does not differentiates two kinds of avowals, it should be clear by now that, in cases of psychic impairment, it is the deep kind of avowal that really matters. So, it seems that the most satisfactory way in which we could characterize the goal of psychoanalytic therapy within Moran's approach, should go like this: psychoanalytic treatment aims at transforming the patient in such a way that she could deeply avow her psychological condition. I will argue, however, that this characterization is crucially unsatisfactory, mainly due to how Moran conceives of the distinction between the deliberative and the theoretical attitudes.

\subsection{The Goal of Psychoanalytic Treatment}

Psychoanalytic therapy assumes, as we may put it, that the agent's incapacity to satisfy the deeper condition of transparency is caused by the interference of some repressed desire. And, according to Moran, psychic health will be restored when the Transparency Condition (which, if I am right, should be construed as being concerned with the deeper variety) is satisfied:

This goal of treatment, however, requires that the attitude in question is knowable by the person, not through a process of theoretical self-interpretation but by avowal of how one thinks and feels. That is, what is to be restored to the person is not just knowledge of the facts about oneself, but self-knowledge that obeys the condition of transparency. (Moran 2001: 90)

However, which is the feeling or thought that the agent is supposed to deeply avow whenever the psychoanalytic treatment succeeds? It seems that, according to Moran, the feeling or thought at stake should be the repressed, unconscious, one. For the previously quoted text is preceded by the following remark: 
But any such suggestion would neglect, at the very last, the crucial therapeutic difference between the merely 'intellectual' acceptance of an interpretation, which will itself normally be seen as a form of resistance, and the process of working-through that leads to a fully internalized acknowledgement of some attitude which makes a felt difference to the rest of the analysand's mental life. (Moran 2001: 89)

The symptom is, as we know, that Frau Bruggen cannot deeply avow that her husband has not betrayed her, and the stipulated cause is her being unconsciously in love with her son-in-law. Psychoanalytic therapy assumes that by bringing unconscious desire to consciousness the symptom will vanish. The issue is what kind of awareness of the repressed desire is required for the symptom to disappear? It does not reduce to recognizing, in the light of evidence, that she has such monstrous desire. For that statement involves the sort of distance with regard to oneself that is specific to the theoretical attitude and, as a result, such statement would not be first-personal enough. So, in order to avow her love for her son-in-law, she should shift to a deliberative attitude towards it. Her avowal should be the result of her deliberation about whether she ought to have such a desire, that is, whether a certain relation with her son-in-law is worth-desiring. Regarding desires, Moran presents the Transparency Condition as being concerned with the relation between

(c) 'Do I desire that P?'

and

(d) 'Is P worth-desiring?'18

So, it seems then that, if Frau Bruggen were to avow her love for her son-in-law, this could only be done after a proper examination of the question 'Is a loving relation to my son-in-law worthdesiring?' Only after an affirmative answer to this question, could she avow that she is in love with her son-in-law. This avowal might still be of the trivial kind, since it may just accidentally coincide with Frau Bruggen's dispositions toward her son-in-law; and the deeper condition of transparency requires that such a disposition should be permeable (and, therefore, sensitive and not merely coincidental) to whatever conclusion she might have reached. But how could that permeability be reached? There is no hint in Moran's approach about how such permeability could be increased. Psychoanalytic therapy is supposed to help us in this respect, but a detailed characterization of that 
practice within Moran's approach leaves us in the dark: even if Frau Bruggen might trivially avow her initially unconscious desire, and not just recognize its existence in the light of behavioral evidence, nonetheless we still do not know how such a commitment may benefit the real goal, namely: that her psychological dispositions should become more permeable to her decisions, beliefs, and intentions, that is, that Frau Bruggen should satisfy the deeper condition of transparency with regard to her belief 'My husband has not betrayed me'.

Moreover, it is unclear how Frau Bruggen could even trivially avow that she is in love with her son-in-law. For, on the psychoanalytic theory, it was precisely the conflict between this desire and her moral outlook what led the former to repression. How could she later on conclude that such a desire is not horrendous, but worth pursuing? Only if she would modify her moral outlook, but why should she? Why should she think that there is something wrong with her moral outlook? Why not just accept her bad luck, the existence of an unsurmountable conflict between her desires and the moral demands? It is clear that she could only recover her psychic health by means of a certain kind of awareness, if we could make sense of the idea that she should revise her moral outlook in the light of the fact that she has some strong desire; for repression of such a desire has turned out to be of no avail. In other words, we need to make sense of the idea that an agent's deliberation should be permeable to her actual dispositions, and not only the other way round. Moran has surely stressed that our psychological dispositions should be permeable to our decisions and commitments. Now, I am stressing that Frau Bruggen could only overcome her impairment if we could make sense of permeability in the complementary direction. ${ }^{19}$

But how can we make sense of this second direction of permeability? In the coming sections, I will explore this second direction of permeability in the light of Bernard Williams' notion of 'acknowledgement' and Simone Weil's distinction between two notions of necessity; and argue why I think Moran's approach cannot make sense of it.

II

\section{Acknowledgment and Self-Knowledge as an Achievement}

\section{The Notion of Acknowledgment}

Bernard Williams explores the notion of acknowledgment in an attempt to articulate a reasonable view about what may count as an authentic life 
A relevant notion here is acknowledgement. Someone may come to acknowledge a certain affiliation as an identity, and this is neither a mere discovery nor, certainly, a mere decision. It is as though he were forced to recognize the authority of this identity as giving a structure and a focus to his life and his outlook. There are circumstances in which what was earlier $a$ mere recognition offact may come to compel acknowledgement, as when many assimilationist Jews in the 1930s came to acknowledge a Jewish and perhaps a Zionist identity under the thought that there was no way in which without evasion they could go on as though it made no difference that they were Jewish people. (Williams 2002: 203; my emphasis)

This notion of acknowledgement is closely related to Moran's characterization of the kind of awareness that may have healing effects. Moran himself employs the phrase 'fully acknowledgment' to describe the kind of awareness that may have such effects; he talks in a previous quotation about 'a fully internalized acknowledgement of some attitude which makes a felt difference to the rest of the analysand's mental life' (Moran 2001: 89; my emphasis). I have argued however that, in cases of psychic impairment, a double direction of permeability is required to reach that 'fully internalized acknowledgement'. My worry is, as we shall see, that Moran's insistence on the distinction between the deliberative and the theoretical attitudes leaves no room for the second direction of permeability. I will argue, by contrast, that Williams' notion of acknowledgment has no such limitations, and may help us to understand how permeability may go both ways.

In a first approximation, we may say that Williams' notion of acknowledgment is placed in a middle ground between discovery and decision or, in Moran's terms, between the deliverances of the theoretical and the deliberative attitudes. Like the latter, an acknowledgment must include some sort of practical commitment and, like the former, it must include the discovery of some facts about oneself:

Drawn to bind myself to other's shared values, to make my own beliefs and feelings steadier (to make them, at the limit, for the first time into beliefs); I become what with increasing steadiness I can sincerely profess; I become what I have sincerely declared to them, or perhaps I become my interpretation of their interpretation of what I have sincerely declared to them. The sense that I am contributing to this, that is a project, fills out the idea that acknowledgement is more than mere factual discovery, while at the same time the sense that there is discovery involved is related to the need to resist fantasy in 
making sense of my beliefs and allegiances in this way. (Williams 2002: 204)

I see no way, within Moran's approach, in which decision and discovery could come together within a single attitude. For these two elements have been used to identify two exclusive attitudes. Yet, Moran's notion of permeability may, after proper elaboration, help us to make sense of this middle ground. Let us begin with the constraints that our psychological conditions impose upon what an agent may acknowledge.

The importance of resisting fantasy may be illustrated by the plight of the akratic gambler. Someone who was convinced that just by deciding to form an intention (or to engage in a project) they will be able to carry it out, would be indulging in a certain kind of evasion, namely: the same one as an akratic gambler who, oblivious of his psychological dispositions, assumed that, given his decision, he will not gamble any more. Insofar as, in acknowledgment, there is a point of hope or prediction that one will be able to keep faithful to a certain identification, it seems relevant that the agent should avoid, to some degree, distortion and fantasy. In this sense, a commitment that did not take sufficiently into consideration the agent's psychological condition, could hardly be identified as an acknowledgment. And, on the contrary, a statement of fact about one's own psychological condition that was deprived of any practical identification, could not be presented as an acknowledgment at all. ${ }^{20}$

It is clear, then, that acknowledgment comes up as an achievement, both epistemic and practical. For the agent can fail both ways: either by failing to resist fantasy or by being unable to keep faithful to a certain commitment. Needless to say, Williams' main point is that both failures are inextricably interrelated: our psychological dispositions must be permeable to our commitments to some degree, but if our commitments are not sufficiently permeable to our psychological reality, we are bound to fail in our attempt to honor the former. An important consequence of this double permeability is that our psychological dispositions do not constitute a determinate set of beliefs or desires in the light of which to form certain intentions, but are shaped by such commitments and, inversely, the notion of acknowledgment invites us to shape our commitments in the light of some sense of our psychological reality. ${ }^{21}$ Now it is not hard to see why this notion of acknowledgment should be regarded as specifically first-personal.

Diotima's knowledge of her intention to invite Arnheim was presented, at the outset, as a paradigmatic case of first-person authority; a striking feature of which was that she needn't look for evidence to ascertain what her intention was. And lack of evidence, far from diminishing her authority, seemed to enhance it. Yet, we did not reduce the specificity of self-knowledge to this 
peculiarity, since there are other cases in which self-knowledge comes as an achievement, as would be the case if Diotima became in a certain manner aware of the fact that she was in love with Arnheim, or Frau Bruggen recognized in a similar way the corresponding feeling for her son-inlaw. We need, then, to identify the kind of awareness that would make us regard such an achievement as specifically first-personal. We appear to have a clear idea of when it is not - for instance, when either Diotima or Frau Bruggen got to know about their feelings just in the light evidence, as someone else could have done. So, what else is required? Moran suggests that they should avow such feelings. Such an avowal involves, in its trivial version, just a practical commitment which comes with some epistemic immediacy which dispenses with the need for the agent to look for evidence in order to determine whether she has actually acquired such a commitment. Moran insists, however, that, in cases psychic impairment, the avowal at stake should come as an achievement and, therefore, what is required for them is something more profound, 'a fully internalized acknowledgement' of their feelings or, to put it another way, that they should deeply avow such feelings. And, as they may acquire such a commitment, we will have a practical commitment, but they will be prey to the sort of epistemic uncertainty that Williams was so keen to bring out. ${ }^{22}$ And this is what should happen in the significant cases of acknowledgment. In fact, we might use such a notion to characterize a continuum which goes from trivial cases of acknowledgment, like Diotima's intention to invite Arnheim, to more problematic ones, like the acknowledgment of one's identities or one's feelings of love.

Should we, nevertheless, conclude that acknowledgment is strictly first-personal only when no epistemic uncertainty is present? Wouldn't this attitude confuse a Cartesian elucidation of self-knowledge with the raw material we are suppose to account for? It sounds that a good account of self-knowledge should allow for epistemic immediacy whenever it is relevant (like in the trivial cases of acknowledgment or commitment), and retain other specifically first-personal features whenever it is not (like in the deeper, and more complex, ones). Among such features, I have mentioned the capacity to practical commitment, as opposed to regarding one's life as a passing show, as well as the capacity to shape one's psychological condition in the light of such commitments, and vice versa. The notion of acknowledgment seems to satisfy them all. Some may, nevertheless, object that the notion of acknowledgment cannot avoid the risk of perceiving one's life as a passing show, since an agent's acknowledgements derive from some discoveries about herself and, so far, it seems that they should be the outcome of a theoretical attitude, which, as we know, is not specifically first-personal, since it involves looking at oneself in a detached manner. To address this issue, let us introduce the notion of 'receptive passivity'. 


\section{8. 'Being Forced to'}

So far, I have been examining the notion of acknowledgment in the light of the distinction between discovery and decision, which, even if it is alien to the kind of unity required, emphasizes the need to bring together some features which are traditionally regarded as incompatible. Williams mentions, however, another concept which may shed a more unifying light on the notion of acknowledgment, namely, a certain way of being forced to:

It is as though he were forced to recognize the authority of this identity as giving a structure and a focus to his life and his outlook. (Williams 2002: 203; my emphasis)

Even if Williams has explored some related notions in previous writings, he does not say much, in Truth and Truthfulness, about what is involved in this kind of necessity, in this 'being forced to'. ${ }^{23}$ Some light may be shed on this notion, though, by examining Simone Weil's distinction between two notions of necessity (and the corresponding notions of obedience):

Obedience. There are two kinds. We can obey the force of gravity or we can obey the relationship of things. In the first case we do what we are driven to by the imagination which fills up empty spaces. We can affix a variety of labels to it, often with a show of truth, including righteousness and God. If we suspend the filling up activity of the imagination and fix our attention on the relationship of things, a necessity becomes apparent which we cannot help obeying. Until then we have not any notion of necessity and we have no sense of obedience. (Weil 1963: 43)

The first kind of necessity is associated with the sort of necessity that is involved in gravitational forces. Agents are subject to some psychological laws in the same way as bodies are subject to gravity. Weil might, thus, say that the fact the akratic gambler keeps on gambling, despite his decision on the contrary, is an effect of gravity upon his soul. In a more common language, we could say that the akratic gambler yields to his passion as a result of some psychological laws acting upon him, in the same way as the rock may roll down the slope as the result of gravitational forces impinging upon it. And something similar goes for Frau Bruggen's incapacity to get rid of her obsessive behavior. We have no room in this paper to detail the laws that, according to Weil, govern the human soul when it is subject to the order of gravity. Let me just mention that her 
reflections on this matter were deeply affected by the ascension to power of the Nazis in Germany, the Spanish Civil War, and the beginning of the Second World War. She regarded these events as the effects of force upon the human soul. Her notion of force (not be confused with Williams' concept of 'being forced to') is a predecessor of her concept of gravity and was introduced to account for what she took to be the core of The Illiad (cf. Weil 1986). A central negative claim in her approach is that the effort of the will is counterproductive to getting rid of gravity. So, she looks somewhere else for a strategy that might diminish the devastating effects of force, of gravity, upon human beings, which might counteract our disposition to harm each other, as it was dramatically disclosed by the aforementioned historical events. I see in the following quotation the core of her alternative proposal, which I will elaborate in the coming sections:

Action is the pointer of the balance. We must not touch the pointer but the weight. Exactly the same rule applies to opinions. (Weil 1963: 44)

The weights in the balance represent the agent's motivations. If one wished to modify the course of her action by the effort of the will, one would be in a position similar to that of someone who wished to change the direction of the pointer by holding it with their fingers. As soon as they get tired and let it go, the pointer goes, after some pendulum motions, back to the initial position and, as a result, no stable change in the agent's course of action takes place. Weil assumes, in this line of reasoning, that the agent's motivations are rather impervious to the effort of the will, at least in some morally relevant cases. We may use this picture to describe the plight of both the akratic gambler and Frau Bruggen. The akratic gambler could hold the pointer of the balance in a direction away from gambling for a while, but his psychological dispositions, his weights, will ended up orientating the course of his action in the direction that he meant to avoid. Frau Bruggen could repress her being in love with her son-in-law, but this will inexorably give rise to some neurotic behavior which the effort of the will could keep under control only for a while. The question is, then, how can the psychological dispositions that are impervious to the agent's decisions (and will) become permeable? Is there any attitude that Frau Bruggen might adopt to increase this kind of permeability, so that she may end up being able to deeply avow that she has not been betrayed by her husband? To this purpose, let us now turn to the second notion of necessity that appears in Weil's initial quotation. Necessity in this second sense has to do with $a$ certain kind of passivity, which, as I will argue, is alien to the sort of passivity that is involved in the akratic gambler yielding to his passion or Frau Bruggen indulging in her obsessive behavior. 


\section{Receptive Passivity and Double Permeability}

Despite Moran's effort to distance himself from the Cartesian model of self-knowledge, I am convinced that his approach still shares a fundamental assumption with that model, namely, a certain view about the role that passivity and activity should play in an agent's life. Within the Cartesian model, an agent is passive when she yields to passions, or when she contemplates her psychological dispositions and states them from a theoretical perspective; whereas she is active when she forms an intention, makes a decision, and seeks to carry it out despite the strength of her passions. A certain conception of what constitutes an agent's true self lies at the bottom of this way of drawing the distinction between passivity and activity in the life of an agent: I am faithful to my true self whenever I act in the light of reason, whereas, by yielding to passions, I am alienated from it. This conception of the true self shows in Decartes' conception of error as deriving from weakness of the will, and not from any specific limits in human understanding; ${ }^{24}$ but also, and more emblematically, in Kant's conception of moral agents as rational beings who are supposed to keep their natural inclinations at bay and act solely for the sake of reason and, in the end, of duty. ${ }^{25}$ And it will become apparent, in the coming sections, how this contrast between the true self and what is alienated from it, is also involved in Moran's distinction between a deliberative and a theoretical attitude towards oneself. To this purpose, I will sketch a different way in which an agent may be passive which, far from degrading her, plays a crucial role in her development and flourishing. I will emphasize that being passive in such a way should not be confused with adopting a theoretical attitude towards oneself, since being passive in that way[Josep Cor1] is involved in any sort of deliberation, including mathematic demonstration. I will, finally, show how a proper cultivation of the proposed kind of passivity may certainly help someone to recover their psychic health and, in general, increase their capacity to lead a life that may make sense. I am, nevertheless, rather reluctant to claim that such a passivity should belong to one's true self, since it is part of my alternative approach that we cannot make sense of a clear-cut distinction between what constitutes one's true self and what should be alienated from it. And the denial of such a clear divide will be relevant to understanding why a certain kind of passivity lies at the core of the kind of awareness that may have a healing effect.

The notion of passivity I am trying to articulate has to do with Weil's second notion of necessity:

If we suspend the filling up activity of the imagination and fix our attention on the 
relationship of things, a necessity becomes apparent which we cannot help obeying. Until then we have not any notion of necessity and we have no sense of obedience. (Weil 1963: 43; my emphasis)

This notion of necessity, this 'we cannot help obeying', is certainly connected to Williams' experience of 'being forced to', and points to a certain kind of passivity:

To act not for an object but from a necessity. I cannot do otherwise. It is not an action but a sort of passivity. Inactive action. (Weil 1963: 39)

What kind of passivity could this be? Think, for instance, of the sense in which an agent is passive when she follows a mathematic demonstration and accepts its conclusion; or when she modifies her perceptual beliefs in the light of the changes that take place in her environment (for instance, if she lifted up her keyboard, she could not longer believe that her keyboard was on the desk). This sort of passivity is similar to the passivity of a dancer as she lets herself follow a piece of music, or that of an actress, who after assimilating the mentality of a character, lets herself flow during the performance. In all these cases, an order, a sort of necessity, is imposed upon the agent, but that imposition (as opposed to what happens with the strength of passion for the akratic gambler) does not oppress or enslave her, but contributes to her expansion and flourishing. For an agent's life is, at least prima facie, enriched by understanding a mathematic demonstration, by tracking what is going on in her surroundings, by letting her body dance a melody or by playing a character. We may regard all such actions as creative for the agent. This idea may sound a bit too vague and strange and, nevertheless, we have first approached both the akratic gambler and Frau Bruggen as agents who confronted a certain kind of predicament, namely: they degraded themselves by their inability to resist a certain temptation. Correspondingly, we may think that some other actions and attitudes may not degrade the self, but contribute to its development and flourishing. We may, then, talk about such actions and attitudes as being creative for the self. And this notion might be, for now, as vague as the notion of degradation that we have so far taken for granted, and such that provide us with a prima facie access to the kind of predicament that the akratic gambler and Frau Bruggen may confront. In a similar vein, let us grant that we have a prima facie apprehension of the idea of 'being creative for the self', both by contrast with the idea of degradation and by appeal to experiences such as following a mathematic demonstration, and see whether the discussion to come may shed further light on how such creativity is at all possible and what kind of attitude may 
favor it.

In this respect, it is important to distinguish low and receptive passivity. Both sorts of passivity involve necessity, but the kind of necessity at stake in each case is of a rather different nature; or this is, at least, the view that I shall defend. Low passivity is the kind of passivity that the Cartesian Model ascribes to passions and it is low because, by yielding to them, the agent degrades herself. The locus of this kind of passivity is, as we have seen, a conception of the self which distinguishes between those aspects of it which the self truly identifies with and those others which are alienated from it. Within this model, all passions are low because they belong to the alienated self; for, no matter whether any such passion may eventually coincide with the dictates of reason, this coincidence tends to be regarded as merely accidental, since there is always the threat that the strength of any given passion might, at some stage, lead us away from reason. Within this model, low passions constitute a system of forces which the true self must make every effort to keep under control. The sort of necessity involved in low passions is, as we see, similar to those of gravitational or physical forces, and with regard to them the true self may have two fundamental attitudes: either to resist or to yield. Moran surely stresses that the passions of a healthy agent are, to some degree, permeable to her decisions and deliberations. Yet, if passions constitute a system of forces, it is difficult to understand how something that it is not itself a passion could alter a passion. This is an issue which I shall not pursue in this paper, but brings out a further tension between the notion of passion associated with a clear-cut divide between the true and the alienated self, on the one hand; and the need to make sense of Moran's notion of permeability, on the other.

In contrast with low passivity, the kind of necessity involved in receptive passivity has primarily to do with the way the self relates to a certain order, and only derivatively with what may structure the elements that may constitute such an order. Low passivity presupposes a system of forces whose impact the self has to resist and is constantly tempted to yield to. This impact on the self is supposed to be subject to the same kind of necessity that unites the different forces within the system. Relatedly, we may say that the system is blind insofar it is not affected by the way the self may conceive of it and this is why it is so hard to understand how a certain decision that one might make, could affect that order. By contrast, the kind of imposition or impact that the order grasped by receptive passivity has on the self is not blind, since, among other things, it depends on the capacity to perceive such an order. A different issue is what brings together the elements that are perceived by the self, and this may vary from one case to another. That order will not be the same if what is grasped is a mathematical demonstration, the movement of an object, or the 
melody in a piece of music. The point is that the sort of imposition (and, thereby, of necessity) that an agent experiences by being passively receptive, has properties that are alien to the kind of necessity involved in low passions, namely: it is receptive (i.e., tracks an order) and creative (i.e., the agent is enriched by the experience of following the order that is external to her). That is why we may call it 'receptive passivity': passive, insofar as it involves some sort of imposition, and receptive, to qualify the kind of imposition that it is. ${ }^{26}$ Both receptivity and creativity seems to be present in Weil's invitation to expose ourselves to some morally disturbing situations, so that, by paying attention to their moral aspects, we might increase our moral sensitivity and, thereby, enlarge the 'righteous actions which we cannot stop ourselves from doing':

We should do only those righteous actions which we cannot stop ourselves from doing, which we are unable not to do, but, through well directed attention, we should always keep on increasing the number of those which we are unable not to do. (Weil 1963: 39)

As we see, the notion of receptive passivity, of 'we cannot stop ourselves from doing', does not rely on a division the self into its true and its alienated portions; and this is a crucial respect in which receptive passivity contrasts with the notion of low passivity. Yet, once we give up such a divide, we may still talk about some passions being low, but no longer regard all passions as low. The facts that may identify a certain passion as low will depend, as we shall see, on their role in the agent's outlook about what is worth pursuing; and the exercise of receptive passivity may favor not a mere repression of that low passion, but the search of a more appropriate expression of the need lying behind it. This suggests that receptive passivity, far from dividing the self, favors the integration of its many elements, and this circumstance is connected to the role that receptive passivity may play in the recovery of one's psychic health.

In this respect, Moran repeatedly emphasizes that permeability of our psychological dispositions to our decisions and deliberations should count as a criterion of psychic health. I have stressed, however, that the opposite direction of permeability (i.e., that our decisions and deliberations should be permeable to our psychological dispositions) is required in order to specify the goal of psychoanalytic treatment and, therefore, of how psychic health could be recovered by means of a certain kind of awareness. I will try to show how the notion of 'receptive passivity' may take care of this sort of permeability while preserving the practical commitment that Moran so rightly emphasizes as constitutive of a strictly first-personal attitude towards oneself. But how could that be at all possible? Doesn't receptive passivity involve a detached, 
theoretical, attitude towards oneself? The only way in which, according to Moran, an agent may examine her psychological dispositions is by adopting a theoretical attitude towards herself. I should then try to specify the nature of receptive passivity, of 'being forced to', in such a way that it goes beyond the theoretical attitude and show how this disparity may be relevant to psychic health. 27

\section{Receptive Passivity and Psychic Health.}

\subsection{The Experience of Dancing}

The experience of dancing may help us to understand why receptive passivity is essential to the permeability of an agent's decisions to her psychological dispositions. The dancer perceives an order in a piece of music which she expresses in her dancing, in the way she moves her body, but how does this transition from the music to the dancing body take place? We may first think of a certain unimaginative dancer. There are many ways in which a dancer may be rather unimaginative, but I will focus on a particular manner of being dull and unimaginative, namely: the dancer whose bodily movements are guided by a set of rules; it does not matter whether she is actually aware of the rules she is following on each particular occasion or she has instead internalized them to such a point that she no longer needs to rehearse them. In the light of this, we may think of an unimaginative agent whose life were governed by a complex set of rules she has decided to commit herself to. ${ }^{28}$ The problem we are exploring is that the agent's behavior may depart from some such rules, despite her most strenuous effort to keep it under control. This is, needless to say, the plight in which both the akratic gambler and Frau Bruggen are trapped. How could they get out of it? To answer this question, we may have a look at what the graceful dancer does, how she guides her body as opposed to what happens to the unimaginative one. Of course, rules may play a role in graceful dancing, but a limited one. The graceful dancer has a certain experience of her body as she pays attention to the music and her body moves as a result in a certain way. Attention to the music, but also to the emotions and bodily experiences that she senses as deriving from the music, are then essential to her gracefulness, to her ability to let herself dance the music. The unimaginative dancer will certainly have a certain experience of her body and also some emotions will accompany her performance; the worry is rather that she will not experience her body and emotions as being in tune with the music, as being inspired by it. Although this is a matter of degree; the unimaginative dancer may have some such experiences but she would be connected to the music in a rather stereotyped or rigid manner; whereas, we might say that, in the case of the 
imaginative dancer, such experiences are finely and creatively in tune with the music. We may thus say that, in order to be passively receptive to the music, the (graceful) dancer must also be passively receptive to her emotional and bodily experiences as being (or failing to be) finely in tune with the music, she must let the latter inspire the movements of her body. This also goes for other kinds of arts like painting, poetry, theatre, but it may be more obvious in the dancing case.

Gracefulness is certainly absent in both the akratic gambler and Frau Bruggen. A criterion of their recovery would be that their actions are proportional to the circumstances. They know how to make their decisions and commitments transparent to their reflection about the world, but are incapable of a deeper kind of transparency or proportionality. Their actions do not express their beliefs and commitments, despite their effort to keep faithful to them; and, in this sense, they are like an unimaginative dancer who is disrupted as she tried to follow her rules. How to render their actions graceful or proportional to the way they see the world? I suggest that we should try to understand our actions in the light of dance and we may thereby find a means to reach that goal, akin to the means by which the unimaginative dancer may learn to follow the music more gracefully. After all, our actions are a response to the circumstances that we may encounter, but how is the transition between the circumstances and our actions supposed to take place? In the case of the unimaginative agent, by means of a number of rules, but rules are of no use, as we have seen, to Frau Bruggen and the akratic gambler. Let us, then, concentrate on how an agent may gracefully deal with her behavior. Like in graceful dancing, rules may play a role, but a limited one. The agent has a experience of her body as she pays attention to the circumstances and, then, she acts in a certain way which may be proportional to them. And attention to the external world, but also to the emotions and bodily experiences which she senses as deriving from her contact with it, may be essential to her gracefulness, to her ability to let herself behave gracefully.

One might object that, in responding to some circumstances, an agent may be quite unaware of the bodily experiences and the specific emotions that such circumstances may arouse within herself. And this may be quite true as a statistical fact. This is why I had to resort to an artistic experience to pick up some aspects of our experience that may go unnoticed in our ordinary dealings with the most diverse circumstances. It turns out, however, that artistic experience is not specific to certain objects or activities, even though in our culture one tends to confine it to some rather special occasions. So, my claim could be put in a different way: Frau Bruggen could recover her health if she could cultivate an artistic attitude towards the world and herself. And the feature that I consider central to that attitude, is a certain exercise of the capacity which I have named 'receptive passivity', that is: the exercise which involves paying attention to 
the order in the world, as well as to the bodily experiences and emotions that we sense our attention to the world gives rise to, and, then, take some decisions if you like, but also, and crucially, let yourself act. The outcome may be more or less graceful, as one may be more less skillful in exercising this sort of receptive passivity. Much training may be required to become a graceful dancer, and it will no doubt be even more difficult to learn to perceive one's own emotions and bodily experiences both in their details and regarding the significance that each of them may have in one's life. This, of course, goes against the Cartesian naive idea that one is well acquainted with one's own mental life. Given the prevalence of wishful thinking and selfdeception, we must rather assume the opposite: only after a slow process of training, plagued with fears and resistances, may an agent learn to be passively receptive to the different aspects of her experience of the world.

We may now return to the notion of permeability. In the graceful dancer, her decisions as to how to move her body are finely sensitive, permeable, to her emotions and bodily experiences as they are to the order in the music itself. It may make sense, at some stage in the process of learning, that she should distrust her bodily experiences in one or another respect, or even that she might have to learn to look at a piece music from a perspective which does not come natural to her, but only to the end that she may reach a capacity of perception from which her movements will, later on, flow. The same goes for the graceful agent. It is not that she should trust her emotions and bodily experiences in every respect. That would be rather impossible, since, quite often, they go in opposite directions, as Proust and Musil were so keen to show. ${ }^{29}$ But she may learn, first, to discern the different aspects involved in each bodily and emotional response and, then, recognize the significance that is attached to each of them. One may be more or less skillful in this respect and, indeed, there is always the risk of delusion and misperception, as Williams has so much emphasized in introducing the notion of acknowledgment.

Acknowledgment comes, we may now say, as a result of receptive passivity and, like the latter, is vulnerable to all sorts of uncertainties. We may use both notions, 'acknowledgement' and 'receptive passivity', as factive concepts, so that they could only be appropriately applied when the agent succeeds in their exercise; but I'd rather prefer to keep them as activities and skills that may fall short of their best upshot. Of course, some minimal degree of success is required in order to recognize a decision as an acknowledgment at all (that is why the akratic gambler's decision or Frau Bruggen's belief, could not be regarded as such) or as an exercise in receptive passivity, but, beyond that, there is plenty of room for uncertainty as to whether one will be able to keep faithful to one's acknowledgments or whether one's receptive passivity was really finely tuned. And this is 
similar to the uncertainty that may assault the dancer as to whether her dance is really graceful or, on the contrary, it is still stereotyped; and she would often wonder whether there might a different approach to a given piece of music from which a significantly more graceful dance might come out of her.

\subsection{Receptive Passivity and the Theoretical Attitude}

Moran stresses that self-knowledge which derives from a theoretical attitude towards oneself is not specifically first-personal, since such an attitude appears as a mere internalization of the observational perspective available to the third person. Looking at oneself from a theoretical view amounts, on his approach, to looking at one's psychological dispositions and events as a passing show and, therefore, in a detached manner. This alienation from oneself that the theoretical attitude involves is contrasted with the deliberative attitude, where the agent is not at all alienated from the reasons she is examining, but ready to be committed to them. The true self seems then to belong to the deliberative attitude, whereas the theoretical perspective requires one to regard some parts of oneself as alien, as only accidentally one's own. As a result, discovery of theoretical facts about one psychological condition could not have a denser practical import than the discovery that one has a broken leg or that one's car is running out of petrol. All these circumstances should be regarded as just instrumentally relevant to an agent's ultimate goals and values. I am convinced, though, that being passively receptive to one's psychological reality has a more intimate scope and significance. To this purpose I will, firstly, argue that, by being passively receptive to her emotional and bodily responses,${ }^{30}$ the agent 'is forced to' acknowledge some values and goals as articulating her ultimate telos and, in this respect, the significance of such responses will, unlike the findings of the theoretical attitude, go beyond instrumentality. I will thereby conclude that receptive passivity could not belong to the theoretical attitude. In section 11.3, two further senses will be explored in which the deliverances of receptive passivity do not play a merely instrumental role in the agent's development and recovery.

One easy way to motivate my claim about the practical import of receptive passivity is to raise the following question: what is the graceful dancer's true self? It is hard to see what her true self may consist of, what parts of herself should be detached or alienated in her dancing. It seems, on the contrary, that dancing gracefully has to do with integration of music, bodily experiences, emotions, decisions and actions. The point is not detachment, but integration. And how could this integration be reached if she adopted an alienated attitude, like the theoretical one, towards her emotions and bodily experiences in her way to dance gracefully? To put it briefly, to assume that 
the theoretical attitude is appropriate towards one's own emotions and bodily experiences, presupposes a clear-cut (and significant) distinction between the true self and what is alien to it; whereas receptive passivity has been designed to challenge such a divide. So, receptive passivity does not vindicate that our emotions and bodily experiences belong to our true self, but just that such a notion only makes sense within a framework that should be abandoned, and the evaluative notions that, within my alternative approach will emerge, will rather insist on whether an agent expresses herself in a certain action more or less gracefully or rigidly, shallowly or deeply, violently or smoothly, and the like. And some such evaluations may invite a change in the way the agent leads her life.

A consequence of the notion of 'true self' is that our emotions and bodily experiences have a merely instrumental value for the development of the agent. The findings of a theoretical attitude towards oneself should have, as we have seen, a practical import similar to the discovery that the road we intend to drive through was closed. In the same way in which our knowledge about the state of the road my affect our intermediate goals as to how to go to a certain place, or even invite to give up such a trip, so knowledge of our own psychological condition may alter some intermediate goals, but do not contribute to fix what one's ultimate goals should be, since that is a matter that only concerns the true self, as it is paradigmatically stated in Kant's moral theory. We may thus say that the theoretical attitude ensures an instrumental permeability of our deliberations to our psychological condition. My claim is, however, that the kind of permeability that is required to understand the healing character of some kinds of awareness is more profound. Our emotions and bodily experiences should contribute to fix our ultimate telos or, to put it another way, our deliberation about 'How should one live?' cannot start but by listening to our emotions and bodily experiences in the most diverse occasions. ${ }^{31}$ Once we give up the notion of a true self, as is obvious in the case of dancing, then it should be clear that it could not be otherwise: where else should we look first in order to acknowledge a certain telos as one's own?

Some may, finally, reply that, even if receptive passivity should not be construed as belonging to the theoretical attitude, this may not count as a serious challenge to Moran's approach, since receptive passivity could form a part of the other, complementary, attitude, namely: the deliberative one. I have no objection to regard receptive passivity as a deliberative skill, since, as matter of fact, this is the way I think it should be construed. However, in that case, the significance of Moran's distinction between the deliberative and the theoretical attitudes would be severely altered and deflated. In particular, the role of the theoretical attitude in the life of a healthy agent would become rather insignificant, to the point that a persistent tendency to adopt 
that attitude towards oneself may appear as criterion of psychic illness; and, on the other hand, the nature of deliberation should be redesigned, so that emotions and bodily experiences should play a relevant role within it.

\subsection{Psychic Health}

\subsubsection{Expression}

The significance of one's emotions and bodily experiences goes deeper than just contributing to determine one's ultimate goals. Think again of the graceful dancer and how her emotions and bodily experiences are relevant to the movements of her body. It is not just that paying attention to such experiences is instrumentally beneficial to her graceful dancing. We should rather regard as a criterion of a graceful dance that it should express her emotions and bodily experiences as being finely in tune with the order contained in the music. We may thus say that such experiences are constitutive of what may count as a graceful dance insofar as they should be expressed by the dancer through her bodily movements. And the same goes for other sorts of action. The reason why Frau Bruggen was taken to Freud's surgery was that she displayed an obsessive behavior towards her husband; obsessive to the point that everyone in the family could not help noticing it. It was obsessive because it was not proportional to the fact, which she sincerely claimed to believe, that her husband hadn't betrayed her. We may regard Frau Bruggen's obsessive behavior as a rigid, ungraceful, the manifestation of an emotion of hers, namely: her love for her son-in-law. The point is not that she should come to believe, in the trivial sense, that she was in love with her son-in-law. That goal might easily be reached in the light of relevant evidence. The goal of her therapy was that she could relate to this emotion in such a way that she could somehow express it in her life, that is, that her body could appropriately dance the music of being in love. To it another way, Frau Bruggen would only recover her health if she could depart from her ungracefulness and, therefore, if she managed to fully experience her emotion for her son-in-law and act in such a way that such an emotion were sufficiently expressed. ${ }^{32}$ She tried to reach that goal by disguising her feelings under the safe clothes of motherly care, but that was not enough. And, in order to go beyond that, she would have to revise her moral outlook (which so far she took to constitute an essential part of her true self) in the light of her emotions and bodily experiences. This way we come back to the second direction of permeability and apprehend a deeper sense in which our ultimate telos should be inspired by our emotions and bodily experiences if psychic health is to be recovered or maintained. A psychoanalytic approach to the akratic gambler's case would favor a similar account of his plight, only that, in this case, the therapist would still have to find out the need or desire that 
is actually manifested through his compulsion and in want of being properly expressed. To close, let me just mention an important element that stands in the way of the required transformation on the patient's side, and how receptive passivity itself may help us to alleviate it.

\subsubsection{Inner Figures}

In this paper, we have been concerned with the kind of cognitive relation to oneself that is specifically first-personal. This concern presupposes a conception of the agent as being able to look upon herself. Moran has distinguished two ways of relating to oneself which I have connected to the Kantian (and Cartesian) distinction between what constitutes one's true self and what is alienated from it. Now, I would like to briefly suggest how this picture is connected to the experience of guilt, which is the standard source of the kind of obsessive behavior that psychoanalytic therapy is meant to repair. I will, firstly, sketch why I think the experience of guilt involves a certain attitude towards oneself, namely: that of a severe judge, which may, nevertheless, have a more or less extended role in an agent's life; secondly, I will show how the attitude of a severe judge may easily lead to alienation and neurosis, and how the exercise of receptive passivity favors the emergence of an alternative, more unifying, way of relating to oneself, closer to the way a caring mother looks after her offspring or friends take care of each other. And, finally, it will become clear why such a new attitude may help the patient to restore her psychic health.

The experience of guilt has a rather global and devastating effect upon the self. When the agent feels guilty at having done something wrong, she not only feels that she has to provide for some compensation or accept a certain sanction; she also regards herself as worthless, as someone whose life has been called into question. Following on from Gabrielle Taylor, Richard Wollheim and Bernard Williams, ${ }^{33}$ I have argued elsewhere that such an emotion cannot be explained by the mere acceptance, on the agent's side, that she has infringed a principle that she endorses; for the agent may feel guilty even if she doesn't endorse the principle. Further considerations allow me to conclude that the global and devastating effect of guilt can only be explained by the experience of being accused by someone with authority. ${ }^{34}$ The view I defend is that the agency that carries out such an accusation is connected in complex ways to the agent's actual external critics, and it is essentially experienced by her as an inner figure that accuses her or, more exactly, as an inner figure who adopts towards her the role of a severe judge. A life guided by such a figure is prone to fall into the sort of neurosis that Freud originally tried to cure. Frau Bruggen is, in this respect, a standard case. Her obsessive behavior arises as a result of a severe condemnation of her being in love with 
her son-in-law, which leads to repression of such a passion to the point that she is fully unaware of both the existence of such a passion and the fact that it has been condemned. This is the way the inner severe judge acts: no trace is left either of what is censored or of the existence of censorship itself. As a result, a confused experience of anguish may arise, which psychoanalysis may track back to the accusation of such inner agency, whose profile is that of a severe judge.

So, it comes as no surprise that a significant number of people should stress that they do not have any phenomenological experience of such inner figures; for an explanation of such absence should not significantly differ from the way psychoanalysis explains why Frau Bruggen is unaware of her being in love with her son-in-law. Both explanations should be tested in a similar way: firstly, like any causal disposition it may be confirmed by appeal to its behavioral displays;35 and, secondly, by the agent's phenomenology as she may, at some point, learn to experience her own inner figures. Some people experience them quite straightforwardly, some others require some training (like the training required to dance gracefully) to experience them. Once again, artistic production may serve to motivate my point; but not through the experience of producing a work of art, as I have being done so far, but by examining what some such works may reveal about our ordinary experiences. For, in my view, some classic works of art seem to provide a detailed description of the experience of guilt as I understand it, namely: as the experience of being accused by a severe judge. Think, for instance, of Crime and Punishment by Fiodor Dostoievski, Letter to his Father and The Castle by Franz Kafka, Autum Fall by Ingmar Bergman, and Opening Night by John Cassavetes, 36 not to mention the confessions of Agustine and Rousseau, as well as Primo Levi's The Drowned and the Saved.37

It is easy to see, moreover, that the image of one's life being examined by a severe judge permeates the Christian tradition and, certainly, lies at the bottom of the Kantian (and Cartesian) struggle between the true self and its natural inclinations. The latter are to be distrusted and kept under control, since they may only accidentally coincide with the dictates of reason which should inspire the life of the true self. By this simple move, our natural inclinations are alienated and presented as a threat to the agent's ability to be guided by reason alone. Natural inclinations, no matter what they might be on each particular occasion, are already condemned and an unredeemable division within the agent is, thereby, taken for granted. Moran's distinction between the deliberative and the theoretical attitudes, even if meant to get rid of this picture, is still, in my view, trapped by it, given that knowledge of one's own psychological dispositions is reserved to the theoretical attitude, which is, as we have seen, an alienated attitude towards oneself.

I have been arguing that receptive passivity departs in an essential way from that alienated 
attitude towards one's emotions and bodily experiences, since it should be rather interpreted in the light of the way the graceful dancer relates to her own experiences. And, as I have highlighted, the point of view of the graceful dancer is not detachment, but integration, namely: the kind of integration that expression provides. A consequence of a patient exercise of receptive passivity towards those aspects of oneself that may, at any stage, be accessible to that attitude, may gradually give rise to an alternative inner figure as the main perspective from which one looks at one's successes and one's failures, at one's aggressive behavior and one's generous gestures. For receptive passivity sees, behind each misgiving or failure, a need of the self that requires to be properly attended to or expressed. So, whenever the agent distances herself from a certain action or attitude of hers, the complementary move comes as to how what is manifested through that alienated behavior or attitude, could be adequately integrated and expressed. And the way in which this 'how' is explored does not take us back to the theoretical attitude, but to a further exercise of receptive passivity in paying attention to the nuances of one's emotional responses and bodily experiences in the more diverse circumstances. ${ }^{38}$ In any case, it seems clear that the inner figure that may emerge from the exercise of receptive passivity, will be closer to that of a caring mother or a close friend than to that of a severe judge. It comes, then, as no surprise that a patient who is able to shape this inner figure and gives a significant role to it in her life, will reach a kind of integration which a life guided by the figure of a severe judge excludes. ${ }^{39}$

\section{Conclusion}

There is much that I admire in Moran's approach to first-person authority and self-knowledge as an achievement. First of all, his stress that a merely theoretical attitude towards oneself is not intimate enough to be specifically first-personal and, secondly, his attempt to characterize the kind of self-knowledge that constitutes a strictly first-personal achievement. My paper has focused on this second issue and, more specifically, on Moran's characterization of the goal of psychoanalytic treatment, which goes beyond the mere theoretical acceptance of the analyst interpretation, and demands a more intimate, first-personal, awareness of one's own psychological condition.

Although Moran's notions of permeability, transparency and avowal point in the appropriate direction, I have argued that they cannot satisfactorily account for the goal of psychoanalytic treatment, given that they are inspired by a Cartesian picture of the self. In particular, I have shown that, even though Moran proposes a single Transparency Condition and a single notion of avowal, we cannot understand their role in the description of psychoanalytic therapy unless we distinguish between a trivial and a deeper condition of transparency, as well as 
between a trivial and a deep notion of avowal. Armed with these distinctions, we can improve our understanding of psychoanalytic practice. Yet, Moran's clear-cut distinction between the deliberative and the theoretical attitudes is inconsistent with a satisfactory description of such a practice. For, in the light of such a distinction, we cannot make sense of the double direction of permeability and, more specifically, of the sense in which an agent's decisions and projects may be permeable to her psychological condition. I have taken advantage Williams' notion of acknowledgment and Weil's distinction between two notions of necessity, in order to articulate a cognitive way of relating to oneself which is as specifically first-personal as Moran's deliberative attitude and, nevertheless, allows us to account for that complementary direction of permeability. I have appealed to the experience of the graceful dancer, as opposed to the unimaginative one, as a way of elucidating what I mean by being passively receptive to one's own emotions and bodily experiences, and how such an attitude should be distinguished from a theoretical one. I have, finally, sketched how such an exercise of receptive passivity may be crucial in describing the goal of psychoanalytic treatment and, therefore, in helping us to understand how a certain kind of awareness may have a significant healing effect. ${ }^{40}$

\section{References}

Agustine, St. (1998), Confessions. New York: Airmont, trans. H. Chadwick.

Armstrong, D. M. (1968), A Materialist Theory of Mind. London: Routledge and Kegan Paul.

Corbi, J. (2004), 'Normativity, Moral Realism, and Unmasking Explanations', Theoria, 50: 155172.

--- (2006), 'Moral Emotions, Principles, and the Locus of Moral Perception', European Journal of Analytic Philosophy, 2: 61-80.

--- (2007), 'The Mud of Experience and Kinds of Awareness', Theoria, 22/1: 5-16.

--- (MS), 'Guilt as the Internalization of the Structure of Guilt'

Corbí, J. and Prades, J.L:. (2000), Minds, Causes, and Mechanisms: A Case Against Physicalism. Oxford: Blackwell.

Bensusan, H. and Pinedo, M. de (2007), 'When my Own Beliefs are not First-Personal Enough', Theoria, Descartes, R. (1996). Meditations on First Philosophy. Cambridge: Cambridge University Press, trans. John Cottingham.

Dostoyevski, F. (2002), Crime and Punishment. London: Penguin, trans. D. McDuff.

Churchland, P. (1984), Matter and Consciousness, Cambridge, Mass.: MIT Press. 
Finkelstein, R. (2003), Expression and the Inner. Cambridge, Mass.: Harvard University Press. Freud, S. (1973), Introductory Lectures to Psychoanalysis. London, Penguin, trans. James Strachey. Hampshire, S. (1957), Freedom of the Individual. Princeton: Princeton University Press.

Heal, J. (2004), 'Moran's Authority and Estrangement', Philosophy and Phenomenological Research, LXIX: 427-432.

Kafka, F. (1987), Letter to His Father. New York: Schocken, trans. E. Kaiserand and E. Willkins. --- (1998), The Castle. New York: Schocken, trans. Mark Harman.

Kant, I. (1977). Groundwork of the Metaphysics of Morals. Cambridge: Cambridge University Press, trans. M. Gregor.

Kripke, S. (1982), Wittgenstein on Rules and Private Language. Cambridge, MA: Harvard University Press.

Levi, P. (1986), The Drowned and the Saved. London: Abacus, trans. R. Rosenthal. Lycan, W. (1996), Consciousness and Experience. Cambridge, MA: MIT Press.

McDowell, J. (1998), 'Wittgenstein on Following a Rule', in J. McDowell, Mind,Value, and Reality. Cambridge, MA: Harvard University Press.

Mellor, D. H. (1977-78), 'Conscious Belief', Proceedings of the Aristotelian Society, 78: 87-101.

----- (1984), 'In Defense of Dispositions', Philosophical Review, 83, 157-81.

Moran, R. (2001). Authority and Estrangement:An Essay on Self-Knowledge. Princeton: Princeton University Press.

Moya, C. (2004), Moral Responsibility: The Ways of Scepticism. London: Routledge.

Musil, R. (1995), The Man without Qualities. London: Picador, trans. S. Wilkins.

Perls, F., Hefferline, R.F. , and Goodman, P. (1977), Gestalt Therapy. New York: Bantam Book.

Prades, J. E. (2007), 'Endorsement, Reasons, and Intentional Action', Theoria, 22/1: 5-16.

Proust, M. (2003), In Search of Lost Time:Way by Swann's vol. 1. London: Penguin Books, trans. C. Prendergast et al.

Reginster, B. (2004), 'Self-Knowledge, Responsibility, and the Third Person', Philosophy and Phenomenological Research, LXIX: 433-39.

Rousseau, J.-J. (2008). Confessions. Oxford: Oxford University Press, trans. Angela Scholar. Ruskin, J. (2000). Modern Painters, v. 2. Boston: Adamant Media Corporation.

Sartre, J. P. (2003), Being and Nothingness. London: Routledge, trans. H. E. Barnes.

Shoemaker, S. (2003), 'Moran on Self-Knowledge', European Journal of Philosophy, 11: 391-401.

Spinoza, B. (1992). Ethics. Cambridge, Hackett Publishing Company, trans. W. H. White.

Taylor, G. (1985). Pride, Shame, and Guilt: Emotions of Self-assessment. Oxford: Oxford University 
Press.

Weil, S. (1963), Gravity and Grace. London: Routledge, trans. E. Craufurd.

--- (1986), 'The Iliad or the Poem of Force', in S. Miles (ed.), SimoneWeil. An Anthology. New York:

Weidenfeld \& Nicolson, trans. M. McCarthy.

Williams, B (1981), Moral Luck. Cambridge: Cambridge University Press.

--- (1985), Ethics and the Limits of Philosophy. Cambridge, Mass.: Harvard University Press.

---(1993), Shame and Necessity. Berkeley: University of California Press.

---(2002), Truth and Truthfulness. Princeton and Oxford: Princeton University Press.

Wittgenstein (1953), Philosophische Untersuchungen/ Philosophical investigations. Oxford, Blackwell, trans. G. E. M. Anscombe.

Wollheim, R. (1999), On the Emotions, New Haven and London:Yale University Press.

Wright, C. (2001), 'Wittgenstein's Rule-Following Considerations and the Central Project of

Theoretical Linguistics', in C. Wright, Rails to Infinity: Essays on Themes fromWitttgenstein's

Philosophical Investigations. Cambridge, MA: Harvard University Press.

\section{NOTES}

\footnotetext{
1 'She was at that time already in love with Arnheim, who had by this time called on her more than once, but in her inexperience she had no inkling of the nature of her feeling. They talked about what it is..... that ennobles the flesh between the sole of the foot and the crown of the head and transforms the confused impressions of civilized life into harmonious spiritual vibrations. But even this was a great deal, and because Diotima was inclined to caution and always on guard against compromising herself, this intimacy struck her as too sudden, and she had to mobilize truly great emotions, the very greatest, in fact, and where were they most likely to be found? Where everyone has shifted them, to the drama of history. For Diotima and Arnheim the Parallel Campaign was, so to speak, a safety island in the swelling traffic of their souls. They regarded it as clearly fated that they should have been brought together at such an important moment, and they could not agree more that the great patriotic enterprise was an immense opportunity and responsibility for intellectual people... So in Diotima the Parallel Campaign had become inextricably bound up with Arnheim; given way to a copious abundance. Her hope that the great treasures of feeling embodied in the Austrian heritage could be strengthened by Prussian intellectual discipline was now most happily justified, and these impressions were so strong that this normally very correct woman had not realized what a breach of protocol she had committed
} 
in undertaking to invite Arnheim to the inaugural conference. Now there was no retreat; anyway, Arnheim, who sensed how it had happened, found it essentially disarming, however annoyed he was at finding himself in a false position; and His Grace was basically too fond of his friend Diotima to show his surprise beyond his first, involuntary, recoil. He met Diotima's explanation with silence and after an awkward little pause amiably held out his hand to Arnheim, assuring him in the most civil and complementary terms that was welcome, as in fact he was' (Musil 1995: 1789, cf. also 197-199).

${ }^{2}$ I will, later on, emphasize the relevance of psychoanalytic therapy for a satisfactory account of self-knowledge as an achievement, cf. section 5 and ff.

${ }^{3}$ Cf. Williams 1981: ch. 9-10; 1985: ch. 10 and postscript; 1993: ch. 4; and 2002: ch. 8.

${ }^{4}$ Cf. Weil 1963: 38-44.

${ }^{5}$ 'Sartre's case if the akratic gambler who resolves to stop gambling is in some ways a more helpful example for considering the two stances and the contrasting roles of commitment (of oneself) and theoretical knowledge about oneself. For the gambler to have made such a decision is to be committed to avoiding the gaming tables.... But now, at the same time, he does know himself empirically too; he knows his history, and from this point of view his 'resolution' is a psychological fact about him with a certain degree of strength' (Moran 2001: 79; cf. also Sartre 2003: part II, sec. 1).

${ }^{6}$ 'There is one kind of evasion in the empty denial of one's facticity (e.g., one's history of weakness and fallibility), as if to say "Don't worry about my actual history of letting you down, for I hereby renounce and transcend all that". But there is also evasion in submerging oneself in facticity, as if to say, "Of course, whether I will in fact disappoint you again is a fully empirical question. You know as much as I do as to what the probabilities are, and so you can plan accordingly" ' (Moran 2001: 81).

7 'The following chapter takes up the idea of the contrast between deliberative and theoretical stances toward oneself, and the ineliminability of the demands of either of them, beginning with the relatively straightforward case of belief' (Moran 2001: 65).

${ }^{8}$ I take it that the most serious line of reasoning against this possibility comes from Wittgenstein's Private Language Argument, which, in turn, is closely connected to his analysis of rule following (cf. Wittgenstein 1953, Kripke 1982, Wright 2001, McDowell 1998, Finkelstein 2003: ch. 4). ${ }^{9}$ Some approaches to self-knowledge seek to avoid the pitfalls of Cartesianism while accounting for first-person authority in terms of a privileged (although not infallible) observational access to one's own mental states. Such approaches have often a rather different philosophical motivation. 
They aim at rendering first-person authority consistent with physicalism, whereby much in the attraction of such views derives, once again, from an independent philosophical conviction (cf., for instance, Armstrong 1968, Lycan 1996, Mellor 1977-78, and Churchland 1984).

${ }^{10}$ Needless to say, this objection also affects those observational approaches which seek to render first-person authority consistent with physicalism.

11 'In much the same way that his actions cannot be for him just part of the passing show, so his beliefs and other attitudes must be seen by him as expressive of his various and evolving relations to his environment, and not as a mere succession of representations (to which, for some reason, he is the only witness' (Moran 2001: 32).

${ }^{12}$ There is the issue as to how much deliberation is involved in forming an intention or making a decision. Several commentators agree that there is a tendency in Moran to over-rationalize agency (cf. Finkelstein 2003: appendix; Heal 2004; and Prades 2007), to over-emphasize the role of reasons in forming intentions and acquiring beliefs. This is an issue that I will discuss in only one respect. I will argue that Moran's conception of the deliberative attitude is not consistent with an appropriate description of the goal of psychoanalytic treatment and, relatedly, the kind of awareness that has a repairing effect. And, as we shall see, the modifications that are needed in order to provide such a description go in the direction of a less intellectual conception of one's intentions and beliefs.

${ }^{13}$ Moran's distinction is inspired in the akratic gambler's case, which, in turn, is the paradigmatic case for a traditional conception of the self as divided into reason, passion and the will. So, it comes as no surprise that Moran's model falls into the traps of that traditional model and has problems in identifying the kind of awareness that may have healing effects on the agent's psychic health. But this is an issue to be discussed in later sections.

${ }^{14}$ Moran 2001: 62.

15 'Behavioral dispositions' should be interpreted here in a rather neutral way. By using the word 'behavior' I am not assuming that an agent's conduct should be described in any specific vocabulary, like, for instance, a vocabulary deprived of intentional terms. On the contrary, I would be happy to grant that, in order to identify behavioral dispositions, we could avail ourselves of whatever concepts we ordinarily use to identify and explain our conduct.

${ }^{16}$ It seems to me that, contrary to what Moran assumes, contexts where we may find it relevant to raise question (a) are those where we suspect that there is a mismatch between our answer to question (b) and the sort of belief that our behavioral dispositions display. To put it in other words, question (a) is more often raised in a theoretical manner than a deliberative one. Cf. Shoemaker 
2003 and Bensusan \& Pinedo 2007 for a defense of the relevance of question (a*) and, therefore, of (a) raised from a theoretical perspective.

${ }^{17}$ In a similar vein, Moran stresses that 'an avowal of one's belief, by contrast, is not made on any psychologically explanatory basis, and is rather the expression of one's own present commitment to the truth of the proposition in question' (Moran 2001: 89).

18 ' Or he may learn of his own desire in a way that approaches the purely theoretical or behavioral, and is quite different from any reflection on what in the world is good or worth desiring. Such a division between two sorts of consideration may well represent a failure of sorts (of rationality, willpower, or something else), but nonetheless any equivalence between them is not something guaranteed by the logic of the first-person, but looks more like a kind of normative ideal' (Moran 2001: 62) and, similarly: ' ... or answer a question of the form "Is this what I really want?" in terms of considerations of what is worth wanting, and thereby come to clarify the structure of his actual desires. The fact that we do have this capacity should not be controversial, for it amounts to the idea that part of what it is to be a rational agent is to be able to subject one's attitudes to review in a way that makes a difference to what one's attitude is' (Moran 2001: 64).

${ }^{19}$ Bernard Reginster raises an issue which points in the same direction as mine: 'Avowals contribute to self-knowledge, then, by virtue of being also 'reports'. But reporting seems inherently 'third-personal', insofar as it involves the self-distancing of self-objectification. When I know the contents of my mind by avowing them, I therefore seem to occupy both perspectives at the same time. If the two perspectives are not incompatible, on should wonder why Sartre's gambler or the rakehell could not both fully endorse their respective attitudes and invoke them as empirical facts supporting a prediction about the future behavior of the one, or a more favorable assessment of the character of the other. If avowing is also reporting, then there are reports that are also avowals, so that their reliance on the reports as mere empirical facts need not be paradoxical and self-defeating' (Reginster 2004: 438).

${ }^{20}$ To discern one's real psychological condition is a rather complex and endless task. Primo Levi stressed, for instance, how difficult it was for him to determine where the boundaries lied between bath faith and self-deception, as he was considering SS members' reports of their activities during the Nazis regime: 'Now, anyone who has sufficient experience of human affairs knows that the distinction... good faith/bad faith is optimistic and illuminist, and is all more so, and for much greater reason, when applied to men such as those just mentioned. It presupposes a mental clarity that few have, and which even these few immediately lose when, for whatever reason, past or present reality arouses anxiety or discomfort in them. Under such conditions there 
are, it is true, those who lie consciously, coldly falsifying reality itself, but more numerous are those who weigh anchor, move off, momentarily or for ever, from genuine memories, and fabricate for themselves a convenient reality. The past is a burden to them; they feel repugnance for the things done or suffered, and tend to replace them with others.... The silent transition from falsehood to self-deception is useful: anyone who lies in good faith is better off, he recites his part better, is more easily believed by the judge, the historian, the reader, his wife and his children' (Levi 1986: 14).

In a similar vein, Primo Levi emphasizes how hard was to unveil his real experience of liberation from the stereotyped image of it. It took a time to find out that, in contrast with the standard picture, the experience of most survivors was permeated with shame and guilt: 'And, finally, among the testimonies, written or heard, there are also those that are unconsciously stylised, in which convention prevails over genuine memory: 'whoever is freed from slavery rejoices. I too was liberated, hence I too rejoice over it." In all films, all novels, just as in Fidelio the shattering of the chains is a moment of solemn or fervid jubilation, and so was mine. This is a specific case of that drifting of memory I mentioned in the first chapter, and which is accentuated with the passing of years and the piling up of the experiences of others, true or presumed, on the layer of one's own' (Levi 1986: 53). For a rather systematic exploration about the difficulties in discerning aspect's of one's experience underneath the stereotyped imaged of it that one has internalized, cf. Proust 2003: v. 7 and Musil 1995.

${ }^{21}$ Cf. Hampshire 1975, Moran 2001: sec. 2.5 and Williams 2002: ch. 8.

${ }^{22}$ Given the prevalence of self-deception and wishful thinking for the most relevant cases of identification, an agent's first-person authority can certainly be challenged; and the same concerns can also be motivated from a social and political perspective:

'It is not foolish to believe that any social and political order which effectively uses power, and which sustains a culture that means something to the people who live in it, must involve opacity, mystification, and large-scale deception. Reasonable people can believe, contrary to the ideals of liberalism, that human beings cannot live together effectively, at least on any culturally ambitious scale, if they understand fully what they are doing. It is not necessarily foolish to believe these things, but they may not be true, and we can still live in the hope (a hope we shall come back to in the next chapter) that they are not'. (Williams 2002: 232; cf. Weil 1963: 16-7 for the role of imagination in self-deception) 
One could also argue that, with regard to some mental states and attitudes, we cannot endow the agent with first-person authority, not even prima facie. Diotima may have prima facie authority as she ascribes to herself the intention to invite Arnheim to dinner, since only under rather strange circumstances could a third party challenge it intelligibly. It is less clear, however, whether we should endow her with such authority with regard to her feelings towards Arnheim and, if we granted it, her authority could rather easily be put into question. And these goes for many other intentions and emotions, including Frau Bruggen's love for her son-in-law. In fact, it takes the efforts of Marcel Proust or Robert Musil ( Cf. Proust 2003, Musil 1995, as well as endnote 24) to discern the ultimate intentions and emotions involved in a certain action or attitude, and even that is, in the end, rather indeterminate. This fits with the mental ontology that the notion of acknowledgment requires, namely: that our mental states do not constitute a determinate set of desires and beliefs, but are shaped by the process of deliberation and the agent's practical commitments.

${ }^{23}$ This notion is connected with a concept of practical necessity that has thoroughly explored in other writings, namely: a sort of practical necessity that is placed somewhere between the Kantian distinction between a hypothetical and a categorical imperative. Williams' insistence on the moral agent as an agent with a character goes in a similar direction (cf. Williams 1981: ch. 9-10; 1985: ch. 10 and postscript, 1993. ch. 4; and 2002: ch. 8).

${ }^{24}$ 'So what then is the source of my mistakes? It must be simply this: the scope of the will is wider than that of the intellect; but instead of restricting it within the same limits, I extend its use to matters which I do not understand. Since the will is indifferent in such cases, it easily turns aside from what is true and good, and this is the source of my error and sin' (Descartes 1996: 41). A couple of pages later, he concludes: 'The cause of error must surely be the one I have explained; for it, whenever I have to make a judgement, I restrain my will so that it extends to what the intellect clearly and distinctly reveals, and no further, then it is quite impossible for me to go wrong' (Descartes 1996: 43).

${ }^{25}$ This understanding of Kant's conception of morality is, to say the least, favored by a relevant number of texts. Let me just quote a remark on the nature of respect which seems to confirm my interpretation:

'It could be objected that I only seek refuge, behind the word respect, in a obscure feeling, instead of distinctly resolving the question by means of a concept of reason. But though respect is a feeling, it is not one received by means of influence; it is, instead, a feeling of self-wrought by means 
of a rational concept and therefore specifically different from all feelings of the first kind, which can be reduced to inclination or fear. What I cognize immediately as a law for me I cognize with respect, which signifies merely consciousness of the subordination of my will to a law without the mediation of other influences on my sense. Immediate determination of the will by means of the law and consciousness of this is called respect so that this is regarded as the effect of the law on the subject, and not as the cause of the law' (Kant 1997: 4:101).

${ }^{26}$ Carlos Moya seeks to articulate an anti-skeptical project with regard to free will out of the kind of responsibility that an agent may have for her own beliefs. Moya does not focus on the kind of responsibility that an agent may have for the cognitive activities in which she may engage in order to acquire a certain belief, since this line of argument will be prey to the skeptical arguments against responsibility for actions. On the contrary, he stresses that one may be praised or blamed by activities that do not depend on making the right decisions or keeping ultimate control, but on a phenomenon that I would describe as being passively receptive to a certain order: 'As a first step towards a characterization of this sort of control, let us think of someone who is carrying out a rather complicated addition without an electronic calculator. She performs the task carefully and gets the right result. She is praiseworthy on both accounts, and has had control over both the process and its result. It is not a matter of luck that she has got it right. But think what having control amounts to in this case. It does not have to do with choices or acts of will in any important sense. The control she has consists rather in her yielding to the internal structure of the thing itself, the figures and the addition rules. It is, so to speak, a passive form of control, which she exercises precisely in being guided by what is there, in the addition problem. She does not choose the rules. In fact, she would lose control of the process if she chose the rules (or the figures), and she would rightly be blamed if she did that. She has neither chosen nor created either the rules or the figures. They come "from outside" her self or her will. But this does not exclude her having deep control over her belief about the result of the addition' (Moya 2004: 176-7). In a rather interesting way, Moya applies this sort passivity not only to calculations, but to other sorts of scientific activities and also literary creation.

${ }^{27}$ It is difficult to examine the role that receptive passivity should have in the life of an agent without being entangled in some vexed philosophical issues. Let me just mention two of them: the fact-value distinction, and the idea that mental states should just have one or another direction of fit, but not both. In this note, I will mainly argue why we should leave such issues aside for a while, as we discern how receptive passivity may be involved in some paradigmatic experiences. Later on, one might decide to revise one's views on those issues in the light of my discernment of 
such experiences or, on the contrary, challenge that discernment inasmuch as it may conflict with some rather general considerations.

The notion of 'receptive passivity' has certainly been introduced by appeal to some cases where the order to which the agent is receptive seems to be placed outside herself and exist independently of our practices. Some may think that this is true in the case of tracking the movement of an object, and equally so in following a mathematic demonstration; but significantly less external with regard to the personality of a character or the musical order that the actress and the dancer are respectively supposed to follow; and, finally, it is of course even more controversial to apply this idea of externality to the alleged moral aspects on which, according to Weil, an agent must focus her attention. In any case, the answer to the question about how external or internal, how objective or subjective, the order involved in each of these examples may be, will depend on one's stance regarding some vexed issues on the fact-value distinction. I do not think I can ultimately defend my position about receptive passivity without taking sides on such issues. There are views on such questions that are rather favorable to this notion and others that exclude it. I should confine myself to saying, in this respect, that the role that I attribute to receptive passivity presupposes the irreducibility of a certain epistemic ability: aspect perception. This will become clear in the next section, where I appeal to the experience of the graceful dancer as an illuminating exercise in receptive passivity. I will argue that, in order to dance gracefully, she must see the music, her bodily experiences, and her bodily movements as internally connected, as being finely in tune. It is easy to see why aspect perception is involved here. As the dancer practices a new piece of music, part of her getting in touch with such a piece will require some experiences like seeing a certain movement of her arm as fitting (or failing to fit) with the music or as being dull or, perhaps, too emphatic. This will appear to her as the dawning of one or another aspect of the music and her dance. She may invite others, less acute, dancers to see some aspects which, in her view, may help them to embellish their dance and to which they may still be blind. The dawning of an aspect and aspect blindness are constitutive of aspect perception, and such experiences are inescapably present as we listen to a piece of music but also in many other experiences like contemplating a painting or understanding a mathematic demonstration, as Wittgenstein is so keen to stress (cf. Wittgenstein 1953).

Hence, we may just disregard, for the sake of argument, the issue as to the metaphysical significance of the questions such as to whether the order that the agent perceives is internal or external, evaluative or not, and treat them as specific questions of fact that may be raised within a certain discursive practice. To close, let me say that one might also construe the conflict between 
some metaphysical views and the epistemic capacities presupposed in the notion of receptive passivity as an invitation to shift the burden of proof. Instead of objecting to the notion of receptive passivity in the light of a certain general view about the fact-value distinction, we may regard some experiences of receptive passivity as an invitation to revise such general view. This is the way I suggest remarks in next section should be taken, namely, as reflections on certain cognitive experiences whose features differ, at least prima facie, from those of a theoretical attitude. Another issue is whether they should ultimately be distinguished, but this would require me to enter a debate far beyond the limits of this paper.

Some may also be tempted to think that aspect perception is, after all, a kind of perception and, therefore, involves a detached attitude, which we have presented as the hallmark of the theoretical attitude. Hence, we cannot reasonably expect that a certain kind of perception could bring about the sort of transformation that may restore an agent's psychic health. Here again, we are confronted with a vexed philosophical issue closely connected to previous one, since, in this line of reasoning, we are assuming that there could not be a conceptual connection between perceiving a certain fact and being motivated to respond to it in a certain way. So, one is taking for granted that any mental state or attitude should have one or another direction of fit, like beliefs and desires seem to have, but it makes no sense that a single state could connect both directions of fit. It is unclear to me why this possibility should be excluded. I do not see, for instance, how the ability to perceive that a certain conclusion follows from a premise could be conceptually independent of the agent's inclination to take advantage of such a conclusion in certain circumstances. And something similar goes for the perception the moral aspects of a given situation. But, needless to say, there is no room in this paper to discuss this complex issue. Let me, then, ask you to suspend your judgment as to whether aspect perception necessarily involves a detached attitude towards its intentional object, and let us see what we can learn about it by exploring how receptive passivity may (at least, prima facie) differ from the kind of passivity involved in the theoretical attitude, while also seeing how such a disparity may be central to understanding the point of psychoanalytic therapy.

${ }^{28}$ This is the way John Ruskin distinguishes between the unimaginative painter and the imaginative one (cf. Ruskin: 2000: 165).

${ }^{29}$ Cf. Proust 2003 and Musil 1995.

${ }^{30}$ I am not assuming that the agent should only be passively receptive to her emotional and bodily responses. For, on the one hand her responses are after all responses to some features of the world and, on the other hand, I am convinced there is no way in which at least some such features could 
be individuated regardless of how we respond to them. The issue as to how this last claim could be consistent with claiming that such features are, after all, features of the world, would take us into the debate about realism which I meant to sidestep in this paper.

${ }^{31}$ We cannot enter into the complexities of Spinoza's philosophy, but his insistence on the strength of affections and their crucial relevance in defining good and evil, seems to be oriented by a similar intuition (cf. Spinoza: 1992, parts IV and V); in fact, Weil's distinction between two notions of necessity and obedience was directly influenced by Spinoza's views on such matters.

${ }^{32}$ Finkelstein (2003) defends a rather powerful view about self-knowledge and, in particular, examines in some detail how the unconscious vs. conscious distinction relates to the idea of expression. His view in connected in different ways to mine, and his main point on the matter goes like this:

Someone's mental state is conscious if he has an ability to express it merely by self-ascribing it. If he lacks such an ability with respect to one of his mental states, it is unconscious. On this account of the distinction between conscious and unconscious mental states, my intention to read Nick Hornby's most recent novel is conscious not by virtue of my knowing about it, or my knowing about it in a particular way, but by virtue of my being able to express it merely by saying, 'I intend to ready Nick Hornby's most recent novel'. (pp. 120-1)

${ }^{33}$ Cf., in this respect, Taylor 1985 Williams 1993, Wollheim 1999, and Corbi MS.

${ }^{34}$ Cf. Corbi MS for a discussion of this issue. In Corbi 2006, I defend the significance of this conception of guilt for the debate about moral particularism. The fact that an agent's character is partly formed by an internalization of how others talk to her and descriptions of her, is connected to Musil's notion of petrification (cf. Musil 1995: §§ 34-40) and Proust's insistence on the tendency to confuse the stereotyped experience with experience itself (cf. Proust 2003: mainly v. 7). Both writers connect these phenomena to the experience of emptiness and lack of sense.

${ }^{35}$ Cf. Corbi et al. 2000: ch. 3 for a discussion of this issue.

${ }^{36}$ Dostoievski 2002, Kafka 1987, 1988, Bergman 1978, and Cassavetes 1977 [give names of films, as we are deleting references from the bibliography].

${ }^{37}$ Agustine 1998, Rousseau 2008, and Levi 1986.

${ }^{38}$ Gestalt therapy (Cf. Perls et al.: 1977), which I regard as a rather important development of Freud's psychoanalytic theory, offers a detailed account as to how such exercises should be performed in order to transform the main inner figure in the light of which a patient looks upon herself.

${ }^{39}$ This change in the attitude towards oneself plays also a role in the way the agent sees others. As 
is clear in the case of guilt (and even more clearly in that of shame), part of the pressure upon oneself comes from a tendency to adapt to the voice of others, to hear their voices as having normative import. Now that the agent is able to take his own needs into consideration, he is also on the way to set a limit to those voices and, therefore, the agent is less prone to see the others as a threat.

${ }^{40}$ I feel indebted to Manuel García-Carpintero, Diego Lawler, Richard Moran, Josep L. Prades and an anonymous referee of this journal for detailed discussion on various aspects of this paper. I have also benefited from remarks by Carla Bagnoli, Fernando Broncano, Ambròs Domingo, Christopher Hookway, Miracle Garrido, Tobies Grimaltos, Julián Marrades, Verónica Martínez, Carlos Moya, Verónica Peláez, Diana Pérez, Sergi Rosell, Lino San Juan, Vicente Sanfélix, Jennifer Saul, Gianfranco Soldati, and Jesús Vega. Thanks are also due to participants in the XVI InterUniversity Workshop on Philosophy and Cognitive Science (Valencia, March, 27-29, 2006) Segundo Encuentro Hispano-Argentino de Filosofía Analítica (Buenos Aires, September 25-27, 2008), and Mind and Language-2 (Madrid, January 22-23, 2008) for their questions and comments. Let me, finally, acknowledge that research for this paper has been funded by the Spanish Ministry of Science and Innovation (BFF2003-08335-C03-01, HUM2006-08236) and the Valencian Regional Ministry of Culture, Education and Sports (GRUPOS04/48, GV04B-251, ACOMP06/13). 